Views of Inclusive Education from the Perspectives of Pre-service and Mentor Teachers

\author{
Jennifer A. Kurth, Ph.D. \\ University of Kansas \\ Anjali Forber-Pratt, Ph.D. \\ Vanderbilt University
}

Citation: Kurth, J. A., \& Forber-Pratt, A. (2017). Views of inclusive education from the perspectives of preservice and mentor teachers. Inclusion, 5, 189-202. doi:10.1352/2326-69885.3.189 


\begin{abstract}
The trend of inclusive education in the U.S.A., and across the globe, is expanding. Consequently, teacher preparation for inclusive practices is thus a necessary consideration for teacher educators worldwide. An important role in shaping pre-service teacher dispositions comes from school experiences and interactions with mentor teachers. It is through this relationship that pre-service teachers formulate their own attitudes, beliefs and skills around inclusive practices. This paper reports the findings from a set of surveys containing both closedand open-ended responses related to inclusive education from both pre-service (student) and mentor teachers. Analysis of the open-ended responses revealed definitions of inclusive education focused on student deficits, and barriers to implementation of inclusive practices that focused on deficits in the capacity of the environment. Four themes emerged when participants defined inclusion. Both groups of educators further described their perceived barriers to implementing inclusive education for students with disabilities, as well as the concerns they have heard others express as organized by five themes. Implications for teacher preparation, including challenging of deficit-based assumptions, are discussed.
\end{abstract}




\section{Views of Inclusive Education from the Perspectives of Pre-service and Mentor Teachers}

There has been an increasing trend in the U.S.A. towards inclusive education for students with disabilities over the past two decades (McLeskey et al. 2012). This trend is situated within international calls to include people with disabilities in all aspects of society, including schools . However, it appears many teacher preparation programs in the U.S.A. (e.g., (Allday, NeilsenGatti, and Hudson 2013) and internationally (Ahmmed, Sharma, and Deppeler 2014, EriksBrophy and Whittingham 2013, Karni, Reiter, and Bryen 2011) emphasize inclusive education, but schools remain segregated. Thus, there is a growing disconnect between what is taught in teacher preparation programs and fieldwork experiences (Caspersen 2013). With more students being included in general education, teacher programs must prepare new teachers for this reality.

Preparation for inclusive education consists of both orientation of a positive disposition for inclusion, as well as providing teachers with the necessary skills to implement inclusive education. Habitus, as defined by Bourdieu (1977), can be defined as "a system of lasting, transposable dispositions...which functions at every moment as a matrix of perceptions, appreciations, and actions" (Bourdieu, 1977, pp. 82-83). Dispositions can be thought of as "a person's enduring favorable or unfavorable cognitive evaluations, emotional feelings, and action tendencies toward some object or data" (Boone \& Kurtz, p. 281-282, 2002). Simply put, dispositions are the tendencies to act or think in a particular way. The individual develops these dispositions in response to the objective conditions he or she encounters.

Dispositions are formed and influenced by beliefs (Brandes and Crowson 2009), peer groups (Boyer and Tschann 1999), culture (Haviland 1987), and mass media (Petty and Cacioppo 1986). Direct instruction, such as teaching dispositions, can also impact disposition 
formation (Kress 1975). Dispositions have been found to be at least equally as important as knowledge and skills for inclusive teachers (Forlin and Chambers 2011). However, typically, "teachers enter the profession and the initial period of preparation with beliefs about teaching and learning that are intransigent and hard to change" (Jordan, Schwartz, \& McGhie-Richmond, p. 540,2009$)$.

This highlights the importance of the teacher preparation period as a time for reflection, discussion, and challenging feedback from others. Exposure to students with disabilities is also thought to be important in shaping positive dispositions (Park, Chitiyo, and Choi 2010), as is teacher preparation for inclusive practices (Leblanc, Richardson, and Burns 2009). For example, Stanovich and Jordan $(1998,2002)$ found that teachers who are overall more effective with all of their students area also more likely to be skilled in inclusive practices. This finding suggests that effective teachers and teaching practices are effective for all students.

Examining teacher or student teacher dispositions related to inclusion in the context of education is not a new phenomenon (Avramidis, Bayliss, and Burden 2000, Avramidis and Norwich 2002, Beacham and Rouse 2012, Cook, Semmel, and Gerber 1999, de Boer et al. 2012, Proctor and Niemeyer 2001, Soodak, Podell, and Lehman 1998). Collectively, these studies have found that teachers' attitudes and perceptions regarding inclusion are influenced by a plethora of factors including the nature and type of disabilities students have and the level of student support needs (Avramidis and Norwich 2002, Solis et al. 2012).

In the teacher preparation period, student teachers, in the U.S. model, work closely with and are supervised by mentor teachers, also known as field based educators. Mentor teachers are likely to play an important role in shaping dispositions (Rademaker 2013). These mentors also 
bridge the theory to practice gap, and help student teachers gain skills and self-confidence as teachers. Felt competence is important in inclusive education; those teachers who have worked with students with disabilities felt more competent about inclusion than those teachers who had not (Everington, Stevens, and Winters 1999). While teachers express a range of concerns about their skills to implement inclusive education, research consistently finds that teachers who are effective are effective for all students (Stanovich and Jordan 2002, Jordan, Schwartz, and McGhie-Richmond 2009).

It is our belief that student teachers also either explicitly or implicitly adopt attitudes related to inclusion through this mentorship. In terms of a body of research, we have only begun to consider the perceptions of both student teachers and mentor teachers. Kurth and Foley (2014) began to tackle the complex puzzle of inclusive education by documenting interviews and perceptions of both student teachers, mentor teachers, university faculty and fieldwork supervisors in a region in the Southwest of the United States.

Results from this work indicated that student teachers were in fact receiving very mixed and contradictory messages about inclusive education (Kurth and Foley 2014). This study skimmed the surface on what these messages were; the themes regarding inclusive education were largely grouped in terms of physical placement of where students are educated or participation, or engaging in activities in general education settings. These initial themes informed the design of the study presented. The present study, as will be discussed further later, was conducted in the Midwest region of the United States. It was decided, based on this previous study, to focus initially on the student teachers and mentor teachers, not ignoring the importance of other perspectives of fieldwork supervisors and university faculty, but recognizing 
that to reach the level of in-depth understanding and intricacies of the development of dispositions, it was best to have a narrower focus. It is our belief, however, that a future study ought to be conducted to capture these other important viewpoints.

In this study, we set out to document and analyze the ways that student teachers and mentor teachers describe their inclusionary dispositions using a mixed-methods approach. Specifically, we ask, (1) What are student and mentor teacher dispositions related to inclusive education? (2) How do mentor teachers and student teachers define inclusion? and (3) What barriers of inclusive education do mentor and student teachers identify in relation to the fieldwork setting?

\section{Method}

An online 72-item survey concerning perceptions, beliefs, and dispositions of inclusion was undertaken with student teachers and mentor teachers who were enrolled in a university practicum course at a research intensive university located in the Midwest of the United States. Descriptive analyses were performed on the close-ended items, and open-ended items were analyzed using a grounded theory approach to identify themes (Strauss and Corbin 1990).

\section{Participants}

Participants included 43 student teachers seeking special education endorsement and 36 mentor teachers in whose classrooms student teachers were completing fieldwork. Student teachers were seeking Master's of Science in Education degrees in conjunction with initial endorsement in high- or low-incidence disabilities. The teaching endorsement program of study requires students to complete two fieldwork courses in K-12 classrooms, one at the beginning of their program of study coinciding with a methods course, and the other fieldwork course at the 
end of their coursework (a capstone experience). The fieldwork experiences provided opportunities to work with mentor teachers while also completing seminar courses that focused on developing skills and dispositions for the teaching profession, centered on state and Council for Exceptional Children (CEC) teaching competencies. Mentor teachers were experienced educators nominated for experience and quality who provided support for student teachers by allowing these educators to work in their classes, to develop and teach lessons under their supervision, and to provide mentoring and support. Demographic characteristics of the participants are Table 1.

\section{Data Sources}

A 72-item online survey was administered anonymously to study participants using Qualtrics software, an online survey program (www.qualtrics.com) following approved Institutional Review Board procedures. The survey responses included a 4-item Likert scale rating to respond to 58 items with options including: strongly disagree, disagree, agree, and strongly agree. An additional 2 items were open-ended, 5 items required respondents to select either 'general education' or 'special education,' and 7 items were demographic in nature. The survey instrument has adequate reliability (Cronbach's $\alpha=0.785$ ), with questions grouped into eight categories, as seen in Table 2, with the demographic and open-ended categories not reported in Table 2.

The surveys were administered at the beginning of fall semester 2013 and spring semester 2014. Each student teacher enrolled in fieldwork, and their supervising mentor teacher, were emailed a link to the Qualtrics survey within the first week of the semester. A total of 50 student teachers were enrolled over the two semesters, with 43 completing the survey ( $86 \%$ 
response rate). A total of 53 mentor teachers were sent the survey, with 36 completing the survey (68\% response rate). Only completed surveys were included in the analysis, and partially completed surveys were discarded ( $n=1$ student teachers; $n=8$ mentor teachers). These surveys were discarded because only demographic questions had been answered, and therefore deemed unsuitable for further analysis.

\section{Data Analysis}

Data from the online survey were analyzed using both quantitative and qualitative methods. Descriptive statistics were utilized to describe participant demographics, mean responses and standard deviations for both groups to each item (mentor teachers and student teachers). Independent samples t-tests were calculated to describe how each group responded to survey items.

To identify the themes from the open-ended items, a grounded theory approach was used (Strauss \& Corbin, 1990). The identified themes allowed the researchers to gain depth of understanding into the lived experiences of the participants regarding inclusive practices. Each author examined these data for patterns in phrases and descriptors related to inclusive education and barriers to implementing inclusive practices. Once individual analyses were completed, inter-observer reliability was established by comparing findings and themes to classify similar responses. Any disagreements were discussed and consensus reached.

\section{Results}

\section{Closed-Ended Survey Responses}

Independent samples t-tests were calculated for mean responses to each survey item for mentor teachers (MT) and student teachers (ST). Levene's test for equality of variances 
determined that equal variances could be assumed; one-tailed tests of significance were calculated. No significant differences between MT and ST were identified.

The survey items were grouped into eight categories based on the overall theme of the questions, and Cronbach's alpha for each group, are reported. As seen in Table 2, mentor and student teachers responded similarly to questions within each of these groups.

While a neutral response option was not provided in the Likert rating scale, the mean responses for most categories were overall neutral. The positive attitudes towards inclusion items ( $n=10$ items) included items such as, "All students can learn important skills in general education settings." Means for both groups were near 2.5 (neutral), with student teachers slightly more positive in their attitudes towards inclusion than mentor teachers. The negative attitudes towards inclusion items ( $n=15$ items) included items such as "some students cannot be effectively included," which was also essentially neutral for both groups, with student teachers slightly more likely to disagree with negative dispositions items than mentor teachers. Placement preferences questions asked participants to select general education or special education as the best place to teach a skill (e.g., "the best or most effective setting to teach social skills"). Again, the overall responses for both mentors and student teachers were neutral, with mentor teachers slightly more favorable towards special education settings.

Similarly, both mentor teachers and student teachers were neutral overall in responses to items about serving hypothetical students in a special education setting ( $n=12$ items) using the 4point Likert scale. A sample item from this category is, "It is best to serve students with selfcare needs, such as a student who needs assistance using the restroom or wears diapers, in a special education setting." Both groups were also neutral in terms of identifying barriers and 
obstacles to inclusion at the fieldwork site $(n=12$ items), with students slightly more likely to identify obstacles than mentor teachers.

While still largely neutral, the means of some categories varied to a greater degree from neutral. For example, mentor teachers were more likely to agree they have the skills and ability to implement inclusion than mentor teachers. A sample item from this category ( $n=4$ items) is, "I have an understanding of ways to adapt an assignment or activity to meet the needs of a student with a disability in a general education setting." Likewise, mentor teachers were somewhat more likely to agree with items representing the category that some students cannot be included than student teachers ( $n=2$ items), which included the items "some students cannot be effectively included" and "to best meet the range of student needs, schools should offer a full range of placement options." Finally, while still overall neutral, student teachers were more likely to agree that inclusion could be implemented to a greater degree in their current fieldwork setting than mentor teachers $(n=5$ items $)$ in their responses to items such as, "in the fieldwork setting, more students could be included in general education academic courses than are currently."

Open-Ended Responses: Defining Inclusive Education

Four themes emerged when mentor teachers (MT) and student teachers (ST) were asked to define inclusion: a) Physical Classroom Placement and Time with General Education Peers, b) Curricular Access, c) Determining “appropriate” Placement, d) Supportive and Meaningful Environment.

\section{Physical classroom placement and time with general education peers}


Under this theme, inclusion was viewed as a physical placement and incorporated elements of percent of time spent with general education peers.

MT1: "A practice in which children with special needs spend most or all of their time with non-disabled peers"

MT3: "Students with disabilities participating in the general education setting with their same age peers."

MT4: "Including individuals with disabilities in all learning environments in a school setting."

ST4: "Inclusion is when a student is in their general education classroom or setting with no support, modifications/accommodations, or support from school personnel.'

ST5: "One with special needs being just as involved as another student in the class in the same manner."

ST6: "Students who receive special education services are placed in the general education classroom and also participate in all school activities as their non-disabled peers."

\section{Curricular access}

Under this theme, access implied that teachers would deliver the standard curriculum (same for all), and that different students will make more or less connections, meaning, and progress in this standard curriculum.

ST11: "Including students with special needs and disabilities within the regular classroom, participating in same activities." 
ST21: "Students being 'included' or having access to the general education curriculum along with activities (field trips)”

ST13: "Inclusion is when students with disabilities are educated in the general education setting with their grade levels peers and have access to general education curriculum." MT15: "All students, no matter their disability, have access to the general education curriculum and environment."

MT25: "Equal opportunities for all students."

\section{Determining "appropriate" placement}

This theme, rooted in the medical model of disability, relates to deeming who is "appropriate" to be educated in inclusive settings, and who makes that decision. The thread defining this theme focuses on trying to 'fix' the student to make him or her conform to the demands of the setting.

MT 12 "Students learning in the regular classroom, with their peers, as much as is appropriate."

MT 33“"Students] participate in as many general education classes as appropriate for his/her level of social and academic performance”

MT27 "Students who receive special education placement and specialized services who successfully participate in as many general education classes as appropriate for his/her level of social and academic performance"

ST38: "Students being included as much as possible with their general education peers"

\section{Supporting and meaningful environment}


Contrary to the previous theme, this is about designing the environment to support students. The roots of this theme are in the social model of disability. MT18 "Including everyone in instruction in the general [education] setting, and differentiating instruction based on the needs of students within the classroom." ST26 "Giving students with special education needs the necessary accommodations and augmentation to be successful in the general education classroom" ST19 "Students who have disabilities receiving their education within the general education classroom given the necessary supports and modifications for them to access the general curriculum." MT8 "Students with disabilities being included in the general education classroom with the accommodations and modifications needed to access the general education curriculum."

Open-Ended Responses: Defining Concerns and Barriers to Inclusive Education Both groups of educators further described their perceived barriers to implementing inclusive education for students with disabilities, as well as the concerns they have heard others express. Five themes emerged: a) Addressing Student Needs, b) Teacher Readiness, c) Capacity of Schools to Serve Students, d) Impact on Students Without Disabilities, e) Fear of "Watering Down" the Curriculum.

\section{Addressing student needs}

This theme identifies concerns about the ability to meet unique student needs in inclusive settings as well as student capacity to benefit from such placement. 
MT8: "There is not one size fits all in any method or philosophy. I do think the child should fully participate as his or her needs allow"

MT24: "The level of teaching that a Sped student needs has to be offered for the student to progress from their starting level. There are advantages of being with peers for

socialization and community for all students, but it is still unclear for many teachers what and how to modify for these students to actually be learning."

ST11: "That it's not being used correctly, we are putting students out that shouldn't be out in the general education"

MT32: "That inclusion is for ALL students. Inclusion should be conducted responsibly and only when the student will gain from the experience."

\section{Teacher readiness}

Mentor and student teachers discussed teacher skills, attitudes, time, and resources that shaped their definition of teacher readiness, and how comfortable they were about implementing inclusive practices in the classroom.

ST19: "The lack of knowledge of how to include students and lack of understanding and use of UDL by general educators."

MT3: "Lack of understanding about how easy it can be to include all students."

ST27: "Teachers think inclusion is when the students with disabilities are in the same room, not working or sitting next to students who are typically developing. Some general educators are great and understand that the students might not be able to do the work but are able to listen, write, help, or be involved in the lessons." 
MT23: "Training staff to provide appropriate support. Time to generate good accommodations and modifications that fit each mainstreamed class Time to meet with regular education teachers in order to be informed of classroom plans."

\section{Capacity of schools to serve students}

Both groups of participants spoke about the capacity of the school environment to support students in inclusive settings. The scope of this theme was outside of the direct classroom environment and focused more globally on the school environment and/or district. MT3: "Not enough time to plan and prepare for children to be successful, especially when behavioral issues are also involved and everyone needs to respond in the same ways and follow a behavior plan."

ST23: "If there are paraeducators in the classroom that they are non-intrusive to the special education students and they help all students in the classroom."

MT29: "While it may afford social opportunities, it is not always the most appropriate academic or life-skill oriented learning situation."

MT30: "Sped teachers can be relegated to high paid [paraeducators] if the [general education] teacher is not provided with a coinciding planning period or the personality of the teacher does not allow for shared teaching and planning. Each student should be considered individually. Full inclusion is not for every child."

\section{Impact on students without disabilities}

This theme identified concerns the groups had regarding students without disabilities in the classroom. 
MT23: "Students with significant cognitive or behavior difficulties disrupt the learning environment for others."

ST9: "Distractions to the "normal" kids"

ST14: "Slowing an entire classroom down while others play catch-up, or leaving behind those who need help, while others move on"

ST29: "The biggest concern that I have seen with inclusion revolves around student pacing and the speed at which many classrooms move at. Sometimes, special education students may not be able to keep up with other students as far as assignments go. This could also lead to a teacher slowing down the classroom which could have harmful affects on general education students."

\section{Fear of "watering down" the curriculum}

Both groups of participants expressed concerns about how curricular modifications would be viewed.

MT4: "I am concerned when I see "adapted" being interpreted as "making things easier" for students."

MT30: "Sometimes the modifications are so significant as to render the inclusion experience insignificant."

ST18: "Students receiving a grade on a subject without documentation on transcripts, yet the curriculum is severely modified"

\section{Discussion}

Limitations 
Prior to delving into the findings, however, there are limitations of this study that must be considered. First, we recognize that the size and diversity of the sample was limited, however we felt it was still a fairly high response rate given the timeframe with which the study took place. We captured opinions of 43 student teachers (out of 50) seeking special education endorsement and 36 mentor teachers (out of 53). This study focused on one geographic region in the Midwestern portion of the United States. However, studies such as this build on previous work (such as Kurth \& Foley, 2014) and help to build a repertoire of studies that examine dispositions about inclusion. It is important that work like this continues particularly as policies and regulations evolve and the landscape of students with disabilities in American schools changes.

Secondly, the research design of this study was a survey instrument. Therefore, the questions were fixed in nature, including the open-ended responses. While a strength of this design is that the same questions were asked to all participants, a weakness of this design is that there was no opportunity for participants to digress on an important topic, or to dialogue with the researchers to dig deeper on particular concepts or examples provided. Therefore, this design may limit potential findings.

Finally, we did not conduct interviews with the faculty members who taught the student teachers, which may have provided additional useful information about the content of student coursework in this teacher preparation program. Even with these limitations, however, the voices of student teachers and mentor teachers provide important information that must be considered across stakeholders and systems in the implementation of inclusive schooling. Despite these limitations, we felt there were additional strengths as well. The survey was done online, so the 
tendency to skip open-ended responses due to ease of typing a response versus handwriting likely contributed to the depth and amount of responses we received.

\section{Dispositions for Inclusive Education}

Analysis of the closed survey responses indicates responses between mentor and student teachers were quite similar, with both groups overall reporting neutral dispositions and beliefs to the survey categories on average. Likert scales presume respondents have some underlying, or latent, continuous variable whose value characterizes the respondents' attitude and beliefs (Clason and Daromdy 1994). The survey was designed without a midpoint option, given concerns about participants' tendency to choose midpoint responses (e.g., Weems \& Onwuegbuzie, 2001). Despite this, mean responses fell overwhelmingly on the midpoint for each category, perhaps indicating a neutral disposition, or possibly indicating that the respondent simply didn't know how to respond (Sturgis, Roberts, and Smith 2014).

Both interpretations of a midpoint mean indicate a failure of respondents, on the whole, to indicate a deeply held conviction about inclusive education. Instead, respondents on average appear to be rather "lukewarm" in their views about inclusive education. This is troubling to inclusion supporters, given the sustained advocacy needed to disrupt segregated education practices and engage in the myriad systems-change activities needed to transform school practices and cultures (Artiles et al. 2006, Sailor 2008-2009, Wedell 2008). It takes a team to achieve full inclusion, and if stakeholders within the school are not willing to take a bold stance, this paints a particularly grim picture for the future of inclusion. Such neutral dispositions may account for assertions that there has been a regression towards more segregated placement for students with significant disabilities (Ryndak et al. 2014). However, while not statistically 
significant, student teachers indicated a somewhat more positive disposition towards inclusive education than mentor teachers in most of the survey categories. Understanding the bases of these subtle differences, including the impact of coursework, faculty dispositions, and school cultures will be needed through additional research activities.

\section{Defining Inclusion}

Interpretations of mentor and student teacher dispositions related to inclusive education depend upon how these groups defined inclusion. Four definitions of inclusion emerged from qualitative analysis of the open-ended responses. Defining inclusion as a place, or as an amount of time spent in general education, was common in both groups. While the context of education is tremendously important in terms of access and participation (e.g., Jackson, Ryndak, \& Wehmeyer, 2008-2009), it is also problematic in that physical placement alone is insufficient to guarantee meaningful access and participation.

In fact, simply being present differs very little from "dumping" a student in a setting. Without appropriate supports and accommodations, it is unlikely that many students with disabilities will be successful in such a circumstance. Such a definition of inclusion assumes the purpose of the practice is exposure or some form of participation, but not necessarily learning, developing, and gaining skills. While being present in the general education classroom is an important step, without the right supports in place, including accommodations, learning for students with disabilities will be unlikely to occur. Learning does not occur through the process of osmosis, and therefore restricting a definition of inclusion to purely physical placement is detrimental. Future educators must not be limited to defining inclusion as physical placement or 
percentage of time in the general education classroom as inclusion. We encourage current and future educators to take a bolder claim on defining inclusion, and put these claims into practice. A second definition of inclusion centered on access to the standard curriculum. Here, access was largely defined as a general education teacher delivering the standard curriculum, with individual students making more or less connections, meaning, and progress in that standard curriculum. This definition is analogous to exposure, rather than mastery (Dymond et al. 2007). This definition assumes that the purpose of inclusion is exposure to core content and general education experiences, again failing to account for student learning and progress. Modern interpretations of inclusive education focus on enhancing educational practices to support all students, including strategies such as universal design for learning and assistive technology (e.g., Wehmeyer, 2009). Implementation of these practices enables all students to learn and make progress in the general curriculum with appropriate accommodations and supports in place, as opposed to simply being exposed to it.

A third definition of inclusion emphasized the need of professionals and other Individualized Education Program (IEP) team members to determine an "appropriate" placement. This definition assumes that there are a variety of placements available, and that students with disabilities can essentially be slotted into a placement to address their unique needs. While the Individuals with Disabilities Education Improvement Act (IDEA; 2004) requires IEP teams to place students in the least restrictive environment to meet their needs, this has been widely misinterpreted to mean a continuum of placement options (e.g., Taylor, 1988). The underlying thread of this theme focuses on needs to 'fix' the student to make him or her ready for the general setting; in other words, the student must learn the skills or behaviors to 
conform to the existing demands of the environment, including teaching styles, curriculum, and supports already in place. This view is firmly rooted in the antiquated medical model of disability (Swain and French 2000) which views disability as a tragedy, and people with disabilities as needing to be fixed or cured. The onus is therefore on people with disabilities to conform to the existing context; such a model is inherently segregationist, assuming that only some students will be appropriate for, and benefit from, some parts of the general education context, and that experts can best make those decisions.

The crux of the medical model of disability is that it is the perception of people with disabilities by the non-disabled majority. Meaning, the voices and opinions of people with disabilities are not included, rather they are squelched by the viewpoints of the dominant culture. In a school-based setting, this definition assumes that the purpose of inclusion is to provide access to those students deemed worthy and capable of learning, and segregated classrooms as the places where learning and preparation for inclusive learning occurs. It is our contention that for students with disabilities, the only appropriate setting is the general education classroom alongside his or her peers, using a range of supports and services including curricular adaptations and co-teaching models.

The fourth and final definition of inclusion from these mentor and student teachers embodies a more modern definition of inclusion, and represents a social model of disability. Participants who defined inclusion within this theme described a student with disabilities as being present in the general education context, with the supports and services provided to the student to be successful. This definition incorporates ideas around designing the environment to support learners, rather than learners being required to gain entry by their ability to conform to 
the existing context. The roots of this theme are squarely within the social model of disability and the systems of supports framework, which focuses on the provision of supports to make contexts meaningful and accessible for all (Thompson et al. 2009). This definition of inclusion assumes that the purpose of including students is to enable all students to learn together, without the need to separate some learners for some activities.

\section{Barriers to Inclusive Education}

Five themes emerged from open-ended responses in which participants identified barriers of inclusive education at the fieldwork setting. The first theme that emerged was a concern about the capacity of schools to adequately meet the unique needs of students with disabilities in general education settings, as well as the capacity of students to benefit from inclusive education. As with definitions of inclusion that focused on appropriateness or readiness, mentor and student teacher responses within this theme assume that some students will not benefit from an inclusive education. Existing research, however, continues to document that students with disabilities have equal, if not superior, outcomes when educated in general education settings, including academic achievement (e.g., Cosier, Causton-Theoharis, \& Theoharis, 2013). Placement in general education settings has also been found to increase teachers' learning expectations for students (Kurth and Mastergeorge 2010). However, respondents indicated that schools and school staff were not yet "ready" to confer such benefits to students with disabilities; instead, participants remained entrenched in current segregated practices. An alternative to this view has been proposed, in which inclusion is defined through the structures and interventions in place (Sailor and McCart 2014). This view focuses on matching support systems to student needs, through the schoolwide application of multi-tiered systems of support, such as response to 
intervention (RTI), thus improving teaching and learning for all students, not only those with disabilities.

A second theme focused on teacher readiness to implement inclusive practices. Mentor and student teacher quotes from this theme focus on teacher skills, attitudes, time, and resources needed for inclusive education. In a 1996 analysis of published investigations of teacher attitudes about inclusive education, Scruggs and Mastropieri found general education classroom teachers were largely supportive of the concept of inclusion, but few thought they had the time, skills, training, and resources needed to implement inclusive education. Over the ensuing 20 years, additional researchers have documented largely similar findings (e.g., Berry, 2010; Cook, 2002; Forlin \& Chambers, 2011). Findings from this analysis contribute to the body of literature documenting teachers holding generally positive attitudes about inclusion as a concept, but real concerns about their ability to implement inclusive practices given their limited time and resources. Again, this theme reiterates the "un-readiness" of current teachers to implement inclusive practices.

A third theme in this analysis was the incapacity of existing schools and systems to serve students with disabilities in inclusive settings. Comments in this theme focused on school- and district-wide shortages and barriers. Concerns such as the availability of resources, including paraeducators, planning time, and other systems characterize this theme, which are common complaints. For example, Santoli and colleagues (2008) surveyed middle school teachers and found teachers did not believe they had adequate time to consult with others, attend meetings, and take on the responsibilities of educating students with disabilities. Examinations of coteaching have further revealed that many teams lack planning time and resources (Magiera and 
Zigmond 2005). However, McLeskey and colleagues (2014) recently outlined features of an effective inclusive elementary school, documenting the structures in place to facilitate inclusion. These authors found school leadership to be a key factor in this effective inclusive school, including the flexible and efficient use of resources, such as scheduling academic instruction at times when resources would be available, along with distributed decision making, data-driven decisions, and high-quality professional development focusing on teacher-identified needs. Continued research into effective inclusive schools is needed, including secondary schools. Without explication and illustration of solutions, many practicing educators will continue to only identify obstacles and remained mired in a system that is not yet "ready" for inclusion.

In addition to concerns about student ability to benefit from inclusive education and teacher ability to deliver inclusive supports, respondents also indicated a concern about the impact of inclusion on students without disabilities. Responses within this theme focused on negative impacts, such as disruption to teaching, or slowing down the pace of instruction. In fact, research has consistently documented that inclusive education has a neutral or positive impact on students without disabilities (e.g., Cole, Waldron, \& Majd, 2004; Kalambouka, Farrell, \& Dyson, 2007; Ruijs, Van der Veen, \& Peetsma, 2010; Salend \& Duhaney, 1999). However, it is likely that these positive benefits are associated with quality implementation of inclusive education, defined as physical placement of students with disabiliteis along with the classroom wide application of supports and services, including RTI and accessible curriculum. As few participants defined inclusive education in this manner, it is possible that their definitions of inclusion which were more akin to "dumping" a student in a classroom would result in few benefits to the student and her or his classmates without disabilities. 
Finally, participants expressed a concern about watering down the curriculum for students with disabilities in inclusive settings. Many of these concerns centered on the appropriateness of accommodations and modifications delivered in inclusive settings, particularly related to grading and promotion implications of modified work. Accommodations and modifications allow access and participation to the core general curriculum, regardless of ability level (Kurth and Keegan 2014, Wehmeyer, Lance, and Bashinski 2002). They can take many forms, including curricular (what is taught), instructional (how content is taught), and alternative outcomes (changing the goals or activities of instruction; Janney \& Snell, 2004). Respondents to this survey appear to have a very narrow definition of accommodations and modifications, in which these dramatically alter the curricular and instructional content, rendering the content so different as to be irrelevant to participation in general education contexts. However, most agree that the general setting is the most appropriate setting in which to gain access to the general curriculum (e.g., Jackson, Ryndak, \& Wehmeyer, 2008-2009), and simply being present in general education settings improves student outcomes (e.g., Cosier \& Causton-Theoharis, 2013). Concerns about grading students with disabilities in general settings, particularly grading modified work, are substantial barriers to inclusive education, particularly in the current era of high-stakes testing. Limited research has documented teacher acceptance of modified work, with existing research suggesting elementary teachers are more willing to accept and grade modified work compared to secondary teachers (Kurth et al. 2012). Further research is needed to understand teacher concerns and implications for assigning grades to students who complete substantially different work in inclusive settings.

Implications 
Empirical research documents positive student outcomes associated with inclusive education (Hughes et al. 2013, Kurth and Mastergeorge 2012, Ryndak et al. 2010). Despite these positive outcomes, high-quality inclusive education is unlikely widely implemented. Educator dispositions are presumed to be a factor in this lack of implementation. The present analysis found a startling disconnect between dispositions when defining inclusive education and dispositions associated with implementing inclusion.

Specifically, definition themes centered on first "fixing" the student to make the student conform to the existing education system, which is a medical model approach to disability (Oyler 2011). This model is thought to alienate and oppress groups of students in schools and society (Frattura and Topinka 2006). However, when identifying barriers and concerns related to implementing inclusive education, educators focused on the lack of capacity of the environment, including teacher training, curriculum, and environmental supports, to implement inclusion, a social model of disability (Hughes and Paterson 1997). These findings suggest a pervasive readiness model, in which both the student and environment need to be fully prepared to benefit from and implement inclusive practices. The concern is that by blaming both student and the capacity of the environment, no amount of preparation will ever be sufficient, and students with disabilities will continue to be relegated to segregated settings and lives. Teacher preparation at the pre- and in-service levels must continue to challenge these deficit-based assumptions and provide alternative solutions to implementing high-quality inclusive education for all students.

Further, the present analyses highlight the need to infuse inclusive education as a disposition and set of skills in teacher preparation programs. General and special educators must feel prepared for inclusive education at a fundamental level; unfortunately, however, inclusion is 
considered an afterthought in many discussions, much like UDL, so that contexts, curriculum, lessons and activities must be retrofitted to make inclusion "work" (Meo 2008). This view enables educators to feel inclusive education is something to be accomplished when the stars align just so, rather than as a set of skills and dispositions that guide development of all contexts, curricula, lessons and activities in a proactive manner.

Finally, these analyses confirm the importance of the fieldwork setting in modeling and teaching both skills and dispositions related to practice. As in other analyses comparing mentor and student teacher definitions and dispositions (e.g., Kurth \& Foley, 2014), respondents here articulated the notion that inclusive education is measured by time and placement in general education classrooms while conveying a number of practical barriers. Extant research documents the impact fieldwork experiences and mentor teachers have on skill and disposition development (Clifford and Green 1996, Hennissen et al. 2011), demonstrating the importance of ensuring the fieldwork setting, and mentor teacher, exemplify the practices and dispositions the teacher preparation institution espouses.

\section{Conclusion}

In this research, we have reported findings from an on-line survey of student and mentor teachers related to inclusive education. Student and mentor teachers largely expressed similar, overwhelmingly neutral, dispositions related to inclusive education. Definitions of inclusive education focused on place and time, rather than supports and services, for both groups, while barriers to inclusion centered on the lack of the school context (curriculum, teachers, and time) to be ready for inclusive services. While there may be differing teacher training models internationally, the universal takeaway is the importance of a mentoring relationship between 
newer and veteran teachers for both individuals to dialogue about inclusive practices and challenges that may arise. The results of this analysis demonstrate the importance of teacher preparation for inclusion, as well as the need to develop of fieldwork experiences that model inclusive practices. Without these substantive changes, inclusive education will likely continue to be misinterpreted, barriers will persist, and the very ideal of inclusion will remain an add-on experience for millions of students with disabilities worldwide. 


\section{References}

"United Nations Convention on the Rights of Persons with Disabilities." Accessed March 30, 2016. http://www.un.org/disabilities/convention/conventionfull.shtml.

Individuals with Disabilities Education Improvement Act. P.L. 108-446.

Ahmmed, Masud, Umesh Sharma, and Joanne Deppeler. 2014. "Variables affecting teachers' intentions to include students with disabilities in regular primary schools in Bangladesh." Disability and Society 29 (2):317-331. doi: http://dx.doi.org/10.1080/09687599.2013.796878.

Allday, R. Allan, Shelley Neilsen-Gatti, and Tina M. Hudson. 2013. "Preparation for inclusion in teacher education pre-service curricula." Teacher Education and Special Education 36 (4):298-311. doi: 10.1177/0888406413497485.

Artiles, A., E. Kozleski, S. Dorn, and C. Christensen. 2006. "Learning in inclusive education research: Re-mediating theory and methods with a transformative agenda." Review of Research in Education 30:65-108.

Avramidis, Elias, Phil Bayliss, and Robert Burden. 2000. "Student teachers' attitudes towards the inclusion of children with special educational needs in the ordinary school." Teaching and Teacher Education 16 (3):277-293. doi: http://dx.doi.org/10.1016/S0742051X(99)00062-1.

Avramidis, Elias, and Brahm Norwich. 2002. "Teachers' attitudes towards integration/inclusion: A review of the literature." European Journal of Special Needs Education 17 (2):129147. doi: http://dx.doi.org/10.1080/08856250210129056.

Beacham, Nigel, and Martyn Rouse. 2012. "Student teachers' attitudes and beliefs about inclusion and inclusive practice." Journal of Research in Special Educational Needs 12 (1):3-11. doi: http://dx.doi.org/10.1111/j.1471-3802.2010.01194.x.

Berry, Ruth A. 2010. "Preservice and early career teachers' attitudes toward inclusion, instructional accommodations, and fairness: Three profiles." Teacher Educator 45 (2):75-95.

Boone, L.E., and D.L. Kurzt. 2002. Contemporary marketing. Orlando, FL: Harcourt, Inc. Bourdieu, P. 1977. Outline of a theory in practice. Cambridge, England: Cambridge University Press.

Boyer, C.B., and J.M. Tschann. 1999. "Predictors of risk for sexually transmitted disesases in ningth grade urban high school students." Journal of Adolescent Research 14 (4):448462.

Brandes, Joyce A., and H. Michael Crowson. 2009. "Predicting dispositions toward inclusion of students with disabilities: The role of conservative ideology and discomfort with disability." Social Psychology of Education 12 (2):271-289. doi: http://dx.doi.org/10.1007/s11218-008-9077-8.

Caspersen, J. 2013. "The valuation of knowledge and normative reflection in teacher qualification: A comparison of teacher educators, novice, and experienced teachers." Teaching and Teacher Education 30:109-119.

Clason, D.L., and T.J. Daromdy. 1994. "Analyzing data measured by individual Likert-type items." Journal of Agricultural Education 35 (4):31-35. 
Clifford, E.F., and V.P. Green. 1996. "The mentor-protege relationship as a factor in preservice teacher education: A review of the literature." Early Child Development and Care 125:73-83.

Cole, C.L., N.L. Waldron, and M. Majd. 2004. "Academic progress of students across inclusive and traditional settings." Mental Retardation 42 (2):136-144.

Cook, Bryan G. 2002. "Inclusive attitudes, strengths, and weaknesses of pre-service general educators enrolled in a curriculum infusion teacher preparation program." Teacher Education and Special Education 25:262-277.

Cook, Bryan G., Melvyn I. Semmel, and Michael M. Gerber. 1999. "Attitudes of principals and special education teachers toward the inclusion of students with mild disabilities: Critical differences of opinion." Remedial and Special Education 20 (4):199-207 \& 256. doi: http://dx.doi.org/10.1177/074193259902000403.

Cosier, M., J. Causton-Theoharis, and G. Theoharis. 2013. "Does access matter? Time in general education and achievement for students with disabiltiies." Remedial and Special Education 34 (6):323-332. doi: 10.1177/0741932513485448.

de Boer, Anke, Sip Jan Pijl, Wendy Post, and Alexander Minnaert. 2012. "Which variables relate to the attitudes of teachers, parents and peers towards students with special educational needs in regular education?" Educational Studies 38 (4):433-448. doi: http://dx.doi.org/10.1080/03055698.2011.643109.

Dymond, S., Adelle Renzaglia, C. Gilson, and M.T. Slagor. 2007. "Defining access to the general curriculum for high school students with significant cognitive disabilities." Research and Practice for Persons with Severe Disabilities 32 (1):1-15.

Eriks-Brophy, Alice, and JoAnne Whittingham. 2013. "Teachers' perceptions of the inclusion of children with hearing loss in general education settings." American Annals of the Deaf 158 (1):63-97. doi: 10.1177/105381519902200107.

http://dx.doi.org/10.1353/aad.2013.0009.

Everington, Caroline, Brenda Stevens, and Victoria Renner Winters. 1999. "Teachers' attitudes, felt competence, and need of support for implementation of inclusive educational programs." Psychological Reports 85 (1):331-338. doi: http://dx.doi.org/10.2466/PR0.85.5.331-338.

Forlin, C., and D. Chambers. 2011. "Teacher preparation for inclusive education: Increasing knowledge but raising concerns." Asia-Pacific Journal of Teacher Education 39 (1):1732.

Frattura, E., and C. Topinka. 2006. "Theoretical underpinnings of separate educational programs." Education and Urban Society 38 (3):327-344.

Haviland, W. 1987. "The nature of culture." In Cultural Anthropology, edited by C. Levi-Strauss, 32-66. New York, NY: Holt, Rinhart, and Winston.

Hennissen, P., F. Crasborn, N. Brouwer, F. Korthhagen, and T. Bergen. 2011. "Clarifying preservice teacher perceptions of mentor teachers' developing use of mentoring skills." Teaching and Teacher Education 27 (6):1049-1058.

Hughes, B., and K. Paterson. 1997. "The social model of disability and the disappearing body: Towards a sociology of impairment." Disability \& Society 12 (3):325-340. 
Hughes, C., M. Agran, J.C. Cosgriff, and B.H. Washington. 2013. "Student self-determination: A preliminary investigation of the role of participation in inclusive settings." Education and Training in Autism and Developmental Disabilities 48 (1):3-17.

Jackson, L., D.L. Ryndak, and M.L. Wehmeyer. 2008-2009. "The dynamic relationship between context, curriculum, and student learning: A case for inclusive education as a researchbased practice." Research and Practice for Persons with Severe Disabilities 33-4 (41):175-195. doi: doi: 10.2511/rpsd.33.4.175.

Janney, R.E., and M.E. Snell. 2004. Modifying schoolwork: Teachers' guides to inclusive practices. 2nd ed. Baltimore, MD: Paul H. Brooks, Inc.

Jordan, Anne, Eileen Schwartz, and Donna McGhie-Richmond. 2009. "Preparing teachers for inclusive classrooms." Teaching and Teacher Education 25 (4):535-542. doi: http://dx.doi.org/10.1016/j.tate.2009.02.010.

Kalambouka, A., P. Farrell, and A. Dyson. 2007. "The impact of placing pupils wiht special educational needs in mainstream schools on the achievement of their peers." Educational Research 49 (4):365-382.

Karni, Nirit, Shunit Reiter, and Diane Nelson Bryen. 2011. "Israeli Arab teachers' attitudes on inclusion of students with disabilities." British Journal of Developmental Disabilities 57 (113, Pt2):123-132. doi: http://dx.doi.org/10.1179/096979511798967106.

Kress, S.W. 1975. "A study of the modification of children's negative attiitudes towards animals.", Doctoral Dissertation, Cornell University.

Kurth, J.A., and J.A. Foley. 2014. "Reframing teacher preparation: Preparing teachers for inclusive education." Inclusion 2 (4):286-300. doi: 10.1352/2326-6988-2.4.286.

Kurth, J.A., M. Gross, S. Lovinger, and T. Catalano. 2012. "Grading of students with significant disabilities in inclusive settings: Teacher perspectives." Journal of the International Association of Special Education 13 (1):39-55.

Kurth, J.A., and L. Keegan. 2014. "Development and use of curricular adaptations for students receiving special education services." Journal of Special Education 48 (3):191-203. doi: doi: $10.1177 / 0022466912464782$.

Kurth, J.A., and A.M. Mastergeorge. 2010. "Individual education plan goals and services for adolescents with autism: Impact of grade and educational setting." Journal of Special Education 44 (3):146-160. doi: 10.1177/0022466908329825ß.

Kurth, J.A., and A.M. Mastergeorge. 2012. "Impact of setting and instructional context for adolescents with autism." Journal of Special Education 46 (1):36-48. doi: doi.org/10.1177/0022466910366480

Leblanc, L., W. Richardson, and K.A. Burns. 2009. "Autism spectrum disorder and the inclusive classroom: Effective training to enhance knowledge of ASD and evidence-based practices." Teacher Education and Special Education 32 (2):166-179.

Magiera, Kathleen, and Naomi Zigmond. 2005. "Co-Teaching in Middle School Classrooms Under Routine Conditions: Does the Instructional Experience Differ for Students with Disabilities in Co-Taught and Solo-Taught Classes?" Learning Disabilities Research and Practice 20 (2):79-85.

McLeskey, J., E. Landers, P. Williamson, and D. Hoppey. 2012. "Are we moving toward educating students with disabilities in less restrictive settings?" Journal of Special Education 46 (3):131-140. 
McLeskey, J., N.L. Waldron, and L. Redd. 2014. "A case study of a highly effective, inclusive elementary school." Journal of Special Education 48 (1):59-70.

Meo, G. 2008. "Curriculum planning for all learners: Applying universal design for learning (UDL) to a high school reading comprehension program." Preventing School Failure 52 (2):21-30. doi: 10.3200/PSFL.52.2.21-30.

Oyler, Celia. 2011. "Teacher preparation for inclusive and critical (special) education." Teacher Education and Special Education: The Journal of the Teacher Education Division of the Council for Exceptional Children 34 (3):201-218. doi: 10.1177/0888406411406745.

Park, M., M. Chitiyo, and Y.S. Choi. 2010. "Examining pre-service teachers' attitudes towards children with autism in the USA." Journal of Research in Special Educational Needs 10 (2):107-114.

Petty, R.E., and J.T. Cacioppo. 1986. Communication and persuasion: Central and peripheral routes to attitude change. New York, NY: Springer-Verlag.

Proctor, R., and J. Niemeyer. 2001. "Preservice teacher beliefs about inclusion: Implications for early intervention educators." Journal of Early Intervention 24 (1):55-66.

, Provo, UT.

Rademaker, S.M. 2013. "Connective capacity: The importance and influence of dispositions in special education teacher education." University of South Florida.

Ruijs, Nienke M., Ineke Van der Veen, and Thea T. D. Peetsma. 2010. "Inclusive education and students without special educational needs." Educational Research 52 (4):351-390. doi: http://dx.doi.org/10.1080/00131881.2010.524749.

Ryndak, D., D. Taub, C.M. Jorgensen, J. Gonsier-Gerdin, K. Anrdt, J. Sauer, A.L. Ruppar, M.E. Morningstar, and H. Allcock. 2014. "Policy and the impact on placement, involvement, and progress in general education: Critical issues that require rectification." Research and Practice for Persons with Severe Disabilities 39:65-74. doi: 10.1177/1540796914533942.

Ryndak, D.L., T. Ward, Sandra Alper, J.F. Storch, and J.W. Montgomery. 2010. "Long-term outcomes of services in inclusive and self-contained settings for siblings with comparable significant disabilities." Education and Training in Autism and Developmental Disabilities 45 (1):38-53.

Sailor, W. 2008-2009. "Access to the general curriculum: Systems change or tinker some more?" Research and Practice for Persons with Severe Disabilities 33-4 (4-1):249-257.

Sailor, W., and A. McCart. 2014. "Stars in alignment." Research and Practice for Persons with Severe Disabilities 39 (1):55-64. doi: 10.1177/1540796914534622.

Salend, S., and L. Duhaney. 1999. "The impact of inclusion on students with and without disabilities and their educators." Remedial and Special Education 20 (2):114-126.

Santoli, Susan Pitts, John Sachs, Elizabeth A. Romey, and Stephen McClurg. 2008. "A Successful Formula for Middle School Inclusion: Collaboration, Time, and Administrative Support." RMLE Online: Research in Middle Level Education 32 (2):113.

Scruggs, T., and M. Mastropieri. 1996. "Teacher perceptions of mainstreaming/inclusion, 19581995: A research synthesis." Exceptional Children 63 (1):59-74. 
Solis, Michael, Sharon Vaughn, Elizabeth Swanson, and Lisa McCulley. 2012. "Collaborative models of instruction: The empirical foundations of inclusion and co-teaching." Psychology in the Schools 49 (5):498-510. doi: 10.1002/pits.21606.

Soodak, Leslie C., David M. Podell, and Laurie R. Lehman. 1998. "Teacher, Student, and School Attributes as Predictors of Teachers' Responses to Inclusion." The Journal of Special Education 31 (4):480-497. doi: 10.1177/002246699803100405.

Stanovich, P., and A. Jordan. 2002. "Preparing general educators to teach in inclusive classrooms: Some food for thought." Teacher Educator 37 (3):173-185.

Strauss, A., and J. Corbin. 1990. Basics of qualitative research: Grounded theory procedures and techniques. Newbury Park, CA: Sage.

Sturgis, Patrick, Caroline Roberts, and Patten Smith. 2014. "Middle alternatives revisited: How the neither/nor response acts as a way of saying "i don't know"?" Sociological Methods \& Research 43 (1):15-38. doi: 10.1177/0049124112452527.

Swain, J., and S. French. 2000. "Towards an affirmation model of disability." Disability \& Society 15 (4):569-582. doi: 10.1080/09687590050058189.

Taylor, S. 1988. "Caught in the continuum: A critical analysis of the principle of the Least Restrictive Environment." JASH 13:41-53. doi: doi: 10.1177/154079698801300105.

Thompson, James R., Valerie J. Bradley, Wil H.E. Buntinx, R.L. Schalock, K. Shogren, M. Snell, M. Wehmeyer, S. Borthwick-Duffy, D.L. Coulter, E.M. Craig, S.C. Gomez, Yves Lachapelle, R.A. Luckasoon, Al. Reeve, S. Spreat, M.J. Tasse, M.A. Verdugo, and M.H. Yeager. 2009. "Conceptualizing supports and the support needs of people with intellectual disability." Intellectual and Developmental Disabilities 47 (2):135-146. doi: 10.1352/1934-9556-47.2.135.

Wedell, Klaus. 2008. "Confusion about inclusion: Patching up or system change?" British Journal of Special Education 35 (3):127-135. doi: 10.1111/j.1467-8578.2008.00386.x.

Weems, G.H., and A.J. Onwuegbuzie. 2001. "The impact of midpoint responses and reverse coding on survey data." Measurement and Evaluation in Counseling and Development 34 (3):166-176.

Wehmeyer, M. 2009. "Autodeterminacion y la tercera generacion de la practices de inclusion [Self-determination and the third generation of inclusive practices]." Revista de Educacion [Journal of Education] 349:45-67.

Wehmeyer, Michael, Denise Lance, and Susan Bashinski. 2002. "Promoting access to the general curriculum for students with mental retardation: A multi-level model." Education \& Training in Mental Retardation and Developmental Disabilities 37 (3):223234. 
Table 1

Participant Demographics

\begin{tabular}{lcc}
\hline & $\begin{array}{c}\text { Mentor } \\
\text { Teachers }\end{array}$ & $\begin{array}{c}\text { Student } \\
\text { Teachers }\end{array}$ \\
\hline Number of Participants & 36 & 43 \\
Mean Age (in years) & 46 & 32.6 \\
Age Range & $27-59$ & $21-52$ \\
Gender & Male -2 & Male -13 \\
& Female -34 & Female -30 \\
& & \\
Mean Years of Experience Special Education & & \\
Teacher & 5.9 & 1.9 \\
Mean Years of Experience General Education & (range $=3-44)$ & (range $=1-4)$ \\
Teacher & 1.3 & 1.3 \\
Mean Years of Experience as a Paraeducator & (range $=1-3)$ & (range $=1-3$ ) \\
High-Incidence Endorsement Held / Sought & 1.1 & 1.25 \\
Low-Incidence Endorsement Held / Sought & (range $=1-3)$ & (range $=1-4)$ \\
Elementary Level Placement & 21 & 30 \\
Secondary Level Placement & 15 & 13 \\
\hline Note. Some student teachs were working as teachers & 27 & 25 \\
& 9 & 11 \\
\hline
\end{tabular}

Note. Some student teachers were working as teachers without endorsement on teaching waiver 
Table 2

Survey Responses by Item Group for Mentor and Student Teachers

\begin{tabular}{lcccc}
\hline Category & $\begin{array}{c}\text { Number } \\
\text { of Items }\end{array}$ & $\begin{array}{c}\text { Cronbach's } \\
\text { Alpha }\end{array}$ & $\begin{array}{c}\text { MT } \\
\text { Mean }\end{array}$ & ST Mean \\
\hline Positive Attitude Towards Inclusion $^{\text {a }}$ & 10 & .806 & 2.47 & 2.67 \\
Negative Attitude Towards Inclusion $^{\text {a }}$ & 13 & .893 & 2.59 & 2.48 \\
Placement Preferences b $^{\text {b }}$ & 5 & .518 & 1.45 & 1.38 \\
Self-Confidence for Inclusion $^{\text {a }}$ & 4 & .525 & 3.36 & 2.67 \\
Hypothetical Student Placement $^{\text {a }}$ & 12 & .892 & 2.53 & 2.46 \\
Obstacles to inclusion $^{\text {a }}$ & 12 & .684 & 2.48 & 2.57 \\
Some students cannot be included $^{\text {a }}$ & 2 & .894 & 2.82 & 2.55 \\
Inclusion in Fieldwork Setting $^{\text {a }}$ & 5 & .714 & 2.52 & 2.75 \\
\hline
\end{tabular}

Note. $\mathrm{MT}=$ Mentor Teacher; $\mathrm{ST}=$ Student Teacher

aScaled where $1=$ strongly disagree; 2 = disagree; $3=$ agree; $4=$ strongly agree

bsaled where $1=$ general education; 2 = special education 